\title{
Does your personality shape your reaction to your neighbours' behaviour? A spatial study of the diffusion of solar panels
}

\author{
Ante Busic-Sontic*a \\ Franz Fuerst ${ }^{\text {ab }}$
}

*Corresponding author: ab2242@cam.ac.uk

${ }^{a}$ University of Cambridge, Department of Land Economy, 19 Silver Street, Cambridge CB3 9EP, UK

${ }^{b}$ University of Melbourne, Thrive Research Hub, Melbourne School of Design, Parkville Victoria 3010, Australia

Conflicts of interest: none 


\begin{abstract}
Fostering investments in green technologies through social norms is a cost-effective alternative to financial incentives. The success of energy efficiency programmes incorporating social influence methods depends in a large part on the extent to which individuals in a social system consider peer behaviour in their decisions. This study investigates the impact of geographical concentrations of personality traits on peer effects for solar photovoltaic (PV) systems. Using data on the Big Five personality traits of 375,000 individuals and adoptions of solar PV systems across 2,600 postcode districts in the UK, a first-difference fixed effect regression model is estimated to analyse the link between the personality traits and the peer effects. The results suggest that districts with spatial concentrations of Openness to Experience and Conscientiousness exhibit stronger peer effects, but only under settings of low financial subsidies for solar PV systems.
\end{abstract}

Keywords: personality traits; peer effects; social spillover; renewable energy; solar panels; technology diffusion 


\section{Introduction}

Personality traits are crucial for understanding the variations in human behaviour and their interactions with the environment. One of the core differences between people, the willingness to adhere to norms $[1,2]$, can be ascribed to personality characteristics. Differences in personality determine how effectively values of peers can be transmitted [3]. For example, talkative people are exposed to communication more frequently and intensely, therefore increasing the probability to encounter and acquire the values held by the majority of their neighbours.

Against the backdrop to mitigate climate change, many governments have put renewable energy targets on their policy agendas. In view of meeting its binding EU target of $15 \%$ of the energy consumption coming from renewable sources by 2020 [4], the UK has implemented various legislations to increase the uptake of renewable energy systems. One prominent programme covers the feed-in tariffs (FITs) which guarantee a predetermined price for selling electricity from renewable energy systems to the grid [5].

Besides such governmental incentives, the uptake of renewables can be fostered by observing and emulating peer behaviour. Studies show that previously installed solar photovoltaic (PV) systems in a neighbourhood increase the probability of further system adoptions [6-8]. Several reasons are suggested for this relationship out of which two stand out. The first is interpersonal communication such as word of mouth. Talking to neighbours can provide useful information concerning the adoption process which can help in reducing uncertainties in the decision process. The second reason is people's tendency to conform to norms. Seeing an increasing number of solar PV panels on neighbours' roofs can make people more aware of their existence and activate desires to follow the behaviour of the majority. It can be helpful to understand how these two effects can be leveraged for fostering adoptions of green technology instead of using traditional subsidies, such as financial incentives, since it has been shown that social incentives can generate greater changes in behaviour [9]. An 
important step to make effective use of the peer effects is to first understand which people may be influenced by them the most.

We elaborate on the effects of personality traits in domestic decisions to mimic the behaviour of neighbours of investing in solar PV systems in the UK. The contributions are threefold. First, we suggest a theoretical framework for why personality traits are expected to influence social spillovers from peers. Second, by using data from 2,590 postcode districts, this is the first study that measures the impact of personality traits on peer effects for a highcost renewable energy system empirically. Third, it is one of the first studies that uses rigorous econometric modelling to analyse the impact of spatially aggregated personality traits on an economic outcome. The results suggest that for every 100 solar PV installations, postcode districts with above average levels of Openness to Experience and Conscientiousness show on average 2 and 6 additional adoptions, respectively, compared to districts with below average levels of these two personality traits.

The remainder of the article is organised as follows. The next section discusses previous literature on peer effects in the green decision-making realm, followed by the theoretical investigation of the relationship between personality traits and peer effects. Next, the data and methods used for the empirical analysis are described before presenting and discussing the results. The article closes with concluding remarks and policy implications.

\section{Literature review}

Several studies suggest that energy-saving and pro-environmental behaviour can be motivated by social norms [10-12]. People aim to comply with commonly accepted standards because not engaging in such behaviour is considered inappropriate and can result in feelings of guilt [13]. A notable example of the impact of social norms is the field experiment on electricity bills by Allcott [14]. Households received a series of reports which compared their use of electricity to that of their neighbours by indicating whether their consumption 
was below or above the average consumption. The provision of the reports resulted in an average decrease in energy usage by $2 \%$. Fischer [15] reviews more than twenty studies on different feedback reports about home energy consumption and finds typical energy savings between $5 \%$ and $12 \%$ (e.g. feedback on energy costs, meter reading, personalised energy audit, normative comparison). In contrast to the study of Allcott [14], no significant change in energy usage is found if the feedback reports include normative comparison (e.g. with neighbours, national or regional average). It is argued that while high-energy consumers may be incentivised to conserve energy, low-energy users may rather increase their consumption since they are doing relatively well compared to others.

Results are more consistent in studies of peer effects in energy-efficient and renewable technology installations. Fornara et al. [8] find that decisions and attitudes of homeowners' relatives and neighbours regarding green energy devices have significant impact on their willingness to adopt energy efficiency measures, such as solar thermal and PV systems and thermal insulation installations. Bollinger and Gillingham [6] compare uptakes of solar panels across different regions in California and conclude that a higher number of existing installations increases the probability of additional adoptions. They argue that the visibility of the solar panels increases people's awareness and fosters information exchange about the technology which reduces uncertainties associated with the installation process and therefore increases the likelihood of further investments. Similarly, Graziano and Gillingham [7] show in a study in Connecticut, US, that a high installed base of solar PV systems in an area significantly increases succeeding adoption rates, whereby the effect diminishes with distance and time. They also find an impact of the built environment (e.g. housing density) and political affiliation on the adoption rates.

A search of the literature reveals only a few studies that systematically question different reactions to social norms as a consequence of consumer heterogeneity. One study illustrates that individuals respond differently to feedback reports on neighbours' energy consumption 
depending on their personality profiles [16]. It is shown that customising the reports to different personality profiles reduces energy consumption in domestic buildings more compared to standardised reports (i.e. $15.5 \%-20.0 \%$ vs $1.2 \%-11.5 \%$ ). Khashe et al. [17] examine the effectiveness of different social messages such as direct and foot-in-the door requests and compare them with reciprocity requests which obliges people to follow certain norms ${ }^{1}$. The results show that neurotic people have a lower compliance in direct requests, while people who score highly in Openness to Experience comply more in reciprocity requests.

Taken together, these studies support the notion that peers can influence people's green decisions. While some research has been carried out on the relationship between personality traits and peer effects in the energy conservation realm, there remains paucity on this link in the context of high-cost installations of energy efficiency and renewable energy systems. The aim of this study is to narrow this gap by proposing a theoretical framework for the role of personality traits on peer effects and to test the suggested framework for solar PV systems empirically.

\section{Personality traits and peer effects: a theoretical frame-}

\section{work}

We use the Diffusion of Innovation (DoI) model by Rogers [2] to analyse the theoretical link between personality traits and peer effects. The model describes how an innovation is disseminated among members of a social system through certain channels of communication over time. According to the model, the relative speed of the adoption process is influenced by mainly five different categories of attributes: the perceived attributes of the innovation (e.g. complexity, triability), type of innovation-decision (e.g. collective vs. individual), the

\footnotetext{
${ }^{1}$ Different to the direct request, the foot-in-the-door request asks individuals to comply with a very small task that nearly anyone would comply with, before requesting the desired larger outcome (e.g. request to turn off lights in one room before requesting the same for additional rooms). In the reciprocity approach, a small favour or gift is provided before requesting the desired outcome.
} 
extent of change agents' promotion efforts ${ }^{2}$, communication channels and the nature of the social system.

The focus of the present study (as opposed to Rogers') is on the communication channels and the nature of the social system. The communication channels can be broadly categorised into means from outside the social system (e.g. mass media communication) and mechanisms within the social system like interpersonal communications $[2,18]$. We target the latter communication channel since we focus on effects from peers. Both channels can provide basic information about the technology, therefore increasing people's awareness of its existence. Interpersonal communication can additionally transfer experience effects [19]. In contrast to general information, receiving detailed know-how through the experience of previous adopters can reduce uncertainties. For instance, it may clarify if and how much energy is saved by a green energy system.

The nature of the social system determines the degree to which people are linked by interpersonal networks within which norms are transmitted by interpersonal communication. Two key elements of the nature of the social system are its degree of interconnectedness and the diffusion effect. The transmission mechanism of information is stronger in social systems where members are more interconnected. The diffusion effect captures the individuals' possible self-generated pressure to adopt or reject an innovation according to the social system norms as the number of adoptions among peers and corresponding feedback about an innovation increase over time.

Interpersonal communication and a higher degree of interconnectedness through social networks, therefore, facilitate the transmission of information within a social system. It follows that differences in interpersonal communication and social ties affect how well information about a technology is transferred from previous to potential adopters and,

\footnotetext{
${ }^{2}$ According to Rogers [2], a change agent is a person "who influences clients' innovation decisions in a direction deemed desirable by a change agency".
} 
thus, can have an impact on the adoption speed [p. 258,2]. Individuals with more social participations, for example, are expected to adopt new technology earlier than others.

Unlike other diffusion models, such as the widely cited Bass model and most of its extensions $[18,20]$, the DoI model does not assume a homogeneous and fully connected social system, in which potential adopters are equally influenced by their peers and the technology. The advantage of the model is that it allows for heterogeneity at the individual and the aggregate social system level. At the individual level, it assumes heterogeneous responses of potential adopters to influences through communication channels (e.g. advertising, interpersonal communication) [21]. At the aggregate level, the model allows for heterogeneity of the nature of a social system by assuming differences in the importance of social norms and the degree of interconnectedness among its members [2, 21]. As such, the model considers heterogeneity across individuals and the interaction networks between them, so that it is well placed to address the impact of personality traits at different levels of a social system. In addition, by modelling communication channels and the nature of a social system as separate factors, it is possible to distinguish between the underlying mechanisms of the social effects. For example, social learning is attributed to the communication channels, whereas social pressure is captured in the nature of the social system. In aggregate fit models assuming homogeneous populations, however, the social effects are often indistinguishable [22].

The DoI model considers personality as a source for heterogeneous responsiveness to peer influence. However, it is expressed by means of vague terms, such as rationality, intelligence and attitudes toward education, whereby a sophisticated framework for capturing personality is missing. Moreover, the heterogeneity of communication behaviour is assessed in the DoI theory independently from personality variables. The meanwhile widely accepted framework of the Big Five, which conceptualises the structure of personality with five dimensions (Openness to Experience, Extraversion, Conscientiousness, Agreeableness and 
Neuroticism), suggests, however, that communication skills can differ across personalities [23]. We argue, therefore, that personalities with pro-communicational traits, firstly, exchange opinions with others more frequently, and, secondly, are more connected through social networks, possibly being more influenced by peer effects than others. Hence, we extend the model by Rogers [2] and assume the communication channels and the nature of the social system to be an implicit function of the Big Five personality traits which in turn influence the adoption rate of technology:

$$
A R=f(A, T Y, C C(\text { Big5 }), N o S S(\text { Big5 }), C A)
$$

$A R=$ Adoption rate (relative speed with which a technology is adopted by members of a social system).

$f()=$. Function $f$.

$A=$ Attractiveness of a technology, depending on its compatibility, complexity, trialability, observability and relative advantage to conventional technology.

$T Y \quad=$ Type of decision: optional, collective or authority.

$C C=$ Communication channels, depending on the Big Five personality traits.

$N o S S=$ Nature of social system, depending on the Big Five personality traits.

$C A=$ Extent of change agents' promotion efforts.

Typically, conversational people with preferences for company of others are individuals who score highly in Extraversion [23, 24]. Entering conversations concerning novel technologies requires also curiosity and willingness to learn, which is a trait frequently observed with individuals who score highly in Openness to Experience. Neurotic people, on the other hand, can show tendencies of social anxiety and are therefore likely to show less interpersonal communication, while agreeable and conscientious people are generally not associated with either distinctly low or high communication skills [25, 26]. Extraversion, Openness 
to Experience and Neuroticism are therefore expected to influence (1) the communication channels $(C C)$ through interpersonal communication and (2) the nature of the social system $(N o S S)$ through the degree of interconnectedness.

Frequent communication and strong interpersonal networks may facilitate the transmission of peer effects. Whether the peers' views will be considered in the adoption decisions depends additionally on people's readiness to follow norms, which is captured by the diffusion effect of the nature of the social system (NoSS) [2]. Individuals who score highly in Agreeableness tend to agree with the views of others in order to avoid interpersonal conflicts, therefore being more inclined to comply with norms than others [25]. Conscientious individuals tend to show goal-directed behaviour which besides planning and organising includes following rules and norms [27]. Hence, Agreeableness and Conscientiousness are expected to further influence the nature of the social system NoSS through the diffusion effect (i.e. people's readiness to follow norms).

Formally, Equation (1) can be therefore specified as follows:

$$
A R=f\left(C C\left(\gamma\left(\underset{+}{E}, \underset{+}{O}, N_{-}\right)\right), N o S S\left(\delta(\underset{+}{E}, \underset{+}{O}, N), \varepsilon\left(\underset{+}{A}, C_{+}\right)\right), .\right)
$$

$\gamma \quad=$ Interpersonal communication as part of the communication channels $(C C)$.

$\delta \quad=$ Degree of interconnectedness as part of the nature of the social system $(N o S S)$.

$\varepsilon \quad=$ Diffusion effect as part of the nature of the social system $(N o S S)$. A high value indicates a higher readiness to follow norms.

$E, O, N, A, C=$ Extraversion, Openness to Experience, Neuroticism, Agreeableness, Conscientiousness with +/- indicating a positive/negative impact on the corresponding variables $(\gamma, \delta, \varepsilon)$. 
In sum, it is argued that personality trait concentrations in a social system are manifested in peer effects through interpersonal communication $(\gamma)$, social networks $(\delta)$ and readiness to follow norms $(\varepsilon)$, which in turn affect the technology adoption rate $(A R)$ (see Figure 1). It is hypothesised that peer effects are stronger in social systems with personality trait concentrations that are expected to have stronger $\gamma, \delta$ and $\varepsilon$, and vice versa:

H1: Peer effects are stronger in social systems with high concentrations of Extraversion, assuming stronger interpersonal communication and degree of interconnectedness in such systems.

H2: Peer effects are stronger in social systems with high concentrations of Openness to Experience, assuming stronger interpersonal communication and degree of interconnectedness in such systems.

H3: Peer effects are less pronounced in social systems with high concentrations of Neuroticism, assuming weaker interpersonal communication and degree of interconnectedness in such systems.

H4: Peer effects are stronger in social systems with high concentrations of Agreeableness, assuming stronger readiness to follow norms in such systems.

H5: Peer effects are stronger in social systems with high concentrations of Conscientiousness, assuming stronger readiness to follow norms in such systems.

\section{Data}

In April 2010, the UK government introduced a feed-in tariff (FIT) scheme with the intention to foster the deployment of small-scale renewable electricity generation technologies (less than $5 \mathrm{MW}$ ), including solar PV, wind and hydro systems [5]. The state guarantees 


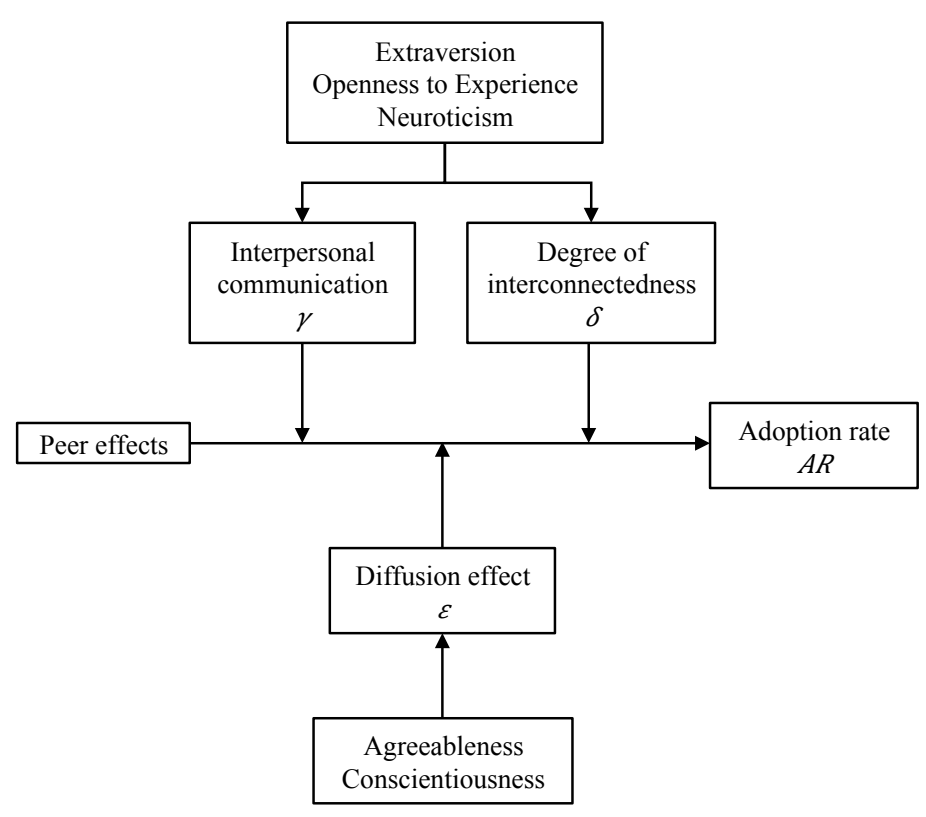

Figure 1: Impact of personality traits on peer effects

the payments of the FITs for a period of 20 to 25 years with a predetermined price scheme for both electricity that is used for own consumption or sold to the grid. The programme introduced an increase particularly in solar panel deployments in the following years. We analyse the adoption patterns of these installations to elaborate on the impact of the Big Five traits on peer effects.

Two main data sources are used for the investigations. The first is provided by the Office of Gas and Electricity Markets (OFGEM) which publishes quarterly data on the renewable electricity generation installations that have been registered under the FIT scheme since its launch in April 2010 [28]. The data contain individual level information on all installations in the UK (except for Northern Ireland), including details on technology type (solar PV, wind, hydro etc.), installed capacity $(\mathrm{kW})$, installation type (i.e. domestic, community, nondomestic), the day of registration and a geographical identification at the postcode district level.

Figure 2 shows the deployment of the domestic solar PV installations under the FIT scheme across the UK from April 2011 to April 2014. It is apparent from these maps that the 
2011

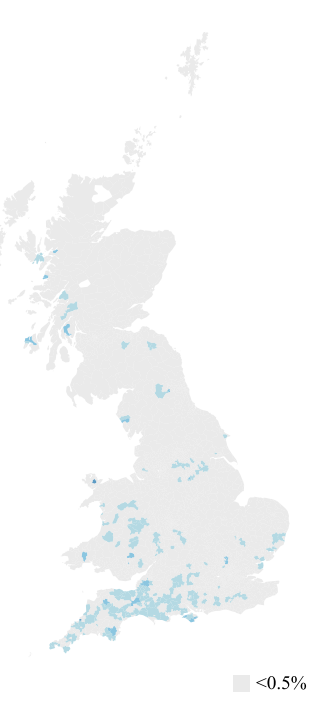

2012

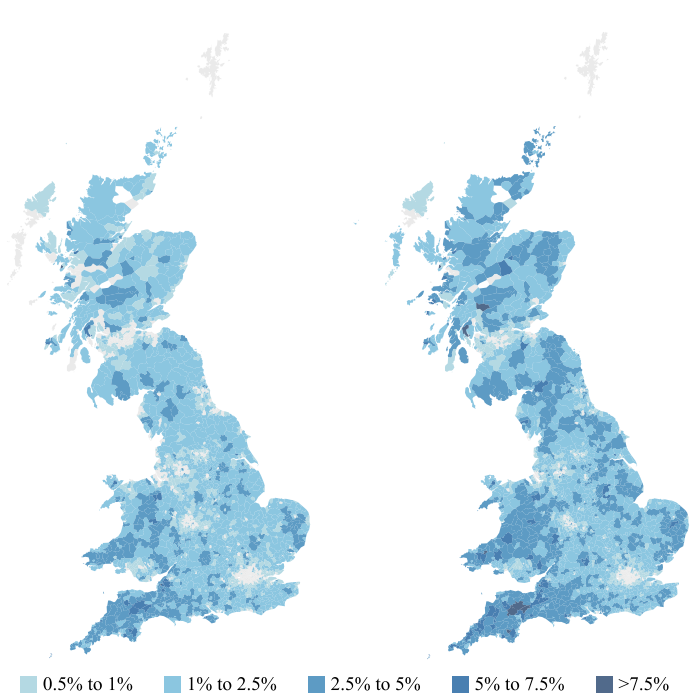

2013
2014

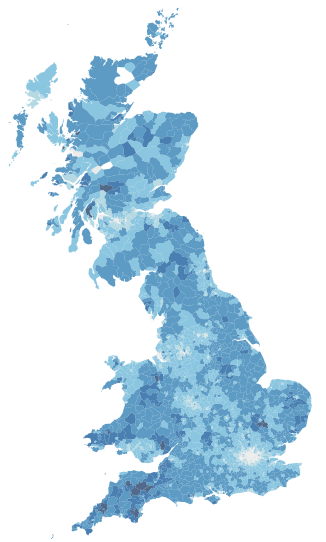

Note: Source: OFGEM [28].

Figure 2: Installation rates of domestic solar PV systems across the UK [coloured]

diffusion speed differs across the postcode districts. After four years of the inception of the FIT scheme, some districts in the north of the UK, for example, show higher installation rates (number of installations per number of dwellings) than districts in the south. It is further evident that solar PV installations tend to cluster spatially. Postcode districts with high installation rates, for example, are concentrated in the South West, Wales and eastern coastal area of England, whereas postcode districts in the South East, North West and specifically in the London area show comparatively lower rates.

The second data set is a large internet-based survey designed and administered by the Department of Psychology, University of Cambridge in collaboration with the British Broadcasting Corporation [29]. Using a 5-item Likert scale, the survey measured the Big Five personality traits of nearly 600,000 individuals across the UK between 2009 and 2011. The total sample after the data cleansing consists of 374,785 individuals (e.g. excluding non-UK residents and uncompleted questionnaires). Geographical indicators allow to match 
aggregated personality traits with the solar PV installations from the OFGEM data source at the postcode district level.

Since the personality traits were surveyed independently from the solar PV installations, the observation periods of the two data sources are not the same. However, based on findings that personality traits are relatively stable throughout time [30-33], we do not expect significant differences in the personality trait patterns for the observation period of the OFGEM data set between 2011 and 2014. This view is also supported by studies that show links between personality traits and genetic factors $[34,35]$. Although attitudes and actions can be influenced by social dynamics [36], we do not expect such impacts to evolve within few years, but rather in the long term.

After matching the personality with the OFGEM data, the mean sample size of individuals per postcode district is 145 (ranging from 1 to 1,138 observations), while 1,295 (50\%) of the 2,590 districts report more than 120 observations. To test the representativeness of each postcode district sample, we follow Rentfrow et al. [37] and compare the number of respondents and socio-demographic variables in a district in the internet-based personality survey with the population characteristics in that district in the UK 2011 Census data $[38,39]$. Figure 3 indicates that the distribution of the number of district respondents in the survey resembles fairly well the Census distribution. The visual impression is supported by a correlation of 0.81 between the number of respondents per postcode district in the survey and the Census population, suggesting a good representation of the districts in the personality data. Regarding ethnicity, the correlations between the number of Black, Asian, White and Mixed ethnicities in the districts and the corresponding Census estimates are 0.94, 0.88, 0.80 and 0.77 , respectively. For median age and education, the correlations are 0.62 and 0.60 , respectively. The correlations indicate that the postcode district samples are fairly representative of the socio-demographic patterns of the local populations. 

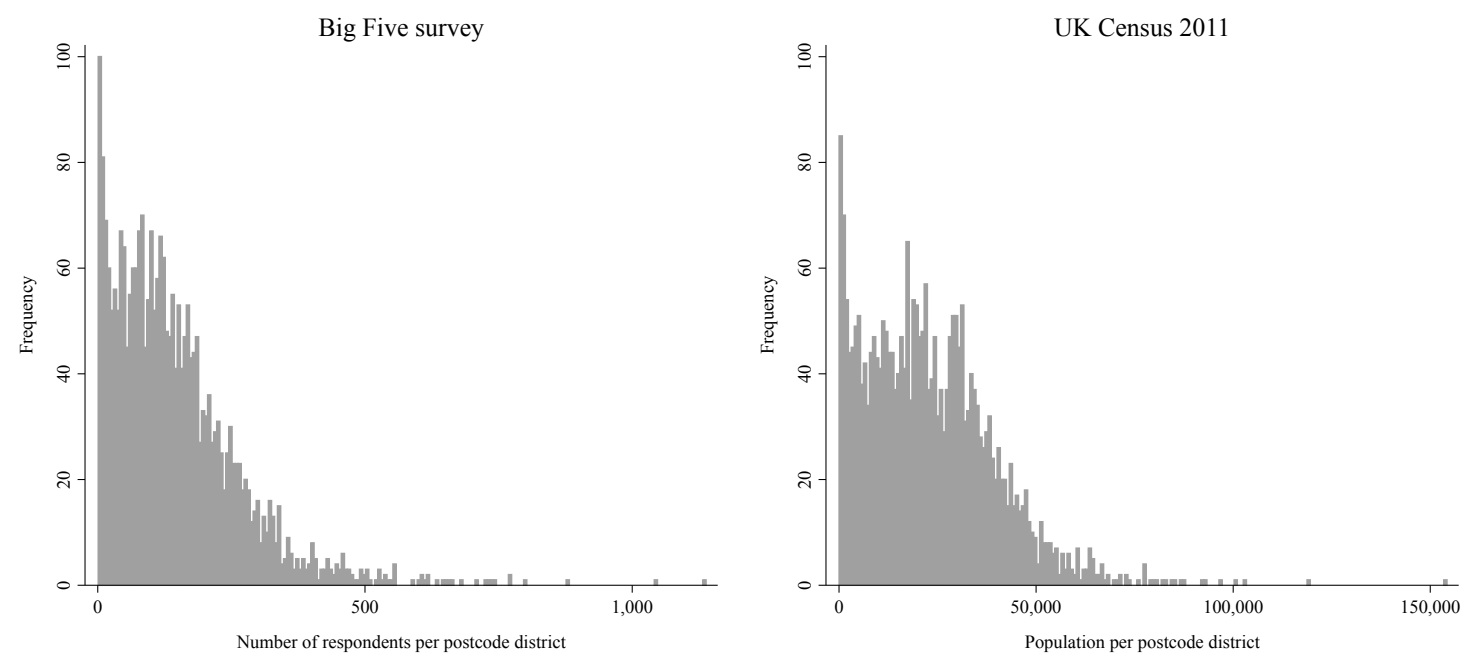

Note: Sources: University of Cambridge (Department of Psychology) and British Broadcasting Corporation [29], Office for National Statistics [38], National Records of Scotland [39].

Figure 3: Distribution of the postcode district samples in the Big Five survey and UK Census 2011 data

The maps displayed in Figure 4 show the spatial concentrations of each of the Big Five personality traits compared to their UK averages. It can be seen that there is a spatial clustering of personality traits across the postcode districts. For example, high levels of Openness to Experience are rather present in the regions of Wales, while districts with low levels of Extraversion are relatively more prevalent in the north western parts of Scotland.

To test the visual impressions of spatial clustering for the solar PV systems and the personality traits, Moran's I measure for spatial autocorrelation is assessed [40]. The Moran' I statistics for the installation rate of solar PV systems are $0.14,0.38,0.44$ and 0.48 for the year 2011, 2012, 2013 and 2014, respectively (statistically significant at the $p=0.01$ level), indicating that the installations are spatially not randomly distributed but that postcode districts with high and/or low installation rates tend to cluster. The increasing value throughout the years suggests that the clustering effect becomes stronger as the number of installations increases. Looking at the Moran's I measure for the Big Five personality traits, it is apparent 

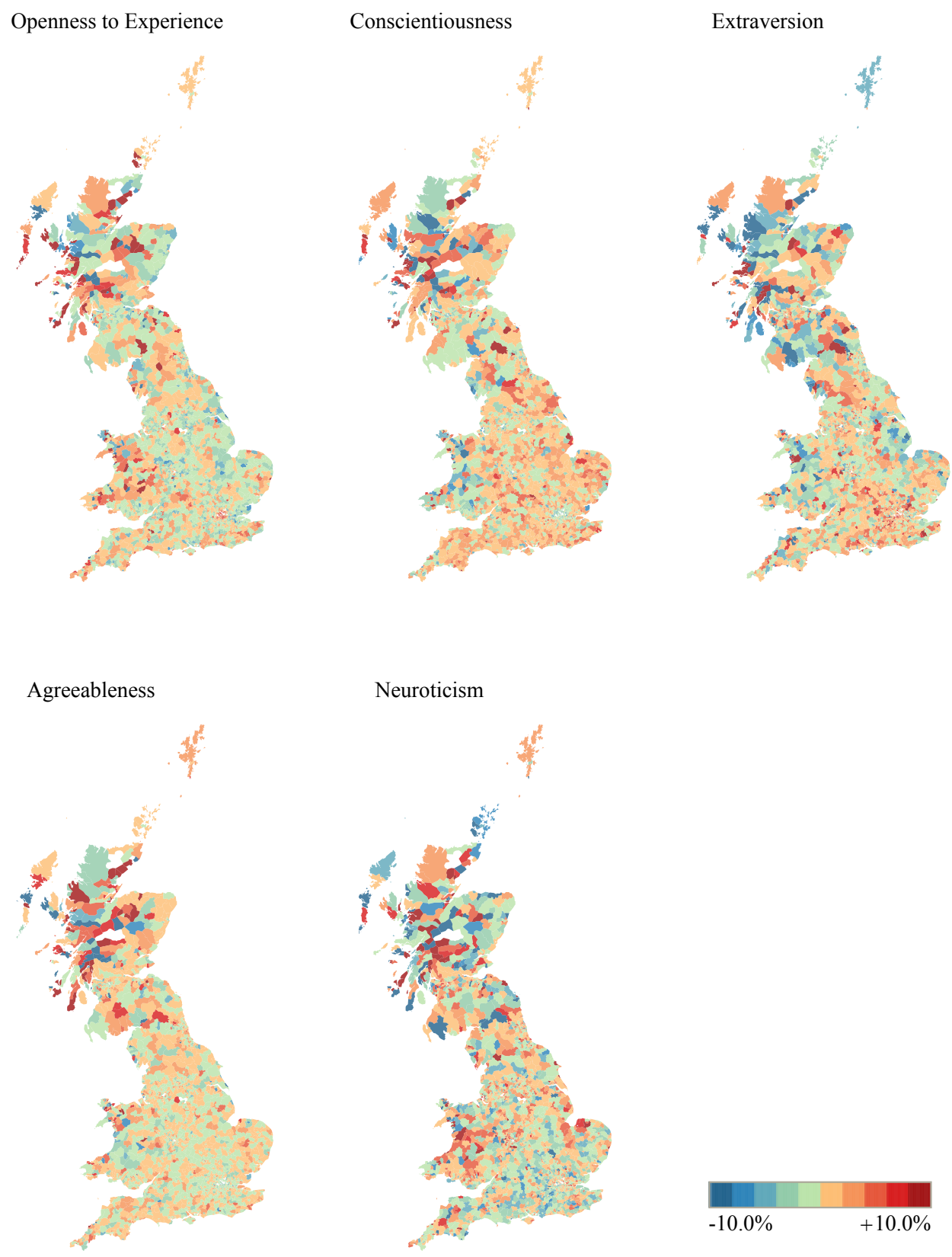

Note: The maps show the deviations of each of the Big Five personality traits to their mean values by postcode districts, measured between 2009 and 2011 [29].

Figure 4: Spatial concentrations of the Big Five personality traits across the UK [coloured] 
that the spatial correlations are weaker compared to the solar panels but still statistically significant: $0.08,0.03,0.07,0.05$ and 0.02 for Openness to Experience, Conscientiousness, Extraversion, Agreeableness and Neuroticism, respectively $(p<0.01)$. As can be seen, the spatial correlation is strongest for Openness to Experience and weakest for Neuroticism.

We further use the 2011 Census data from the Office for National Statistics and National Records of Scotland in our analysis to control for dwelling type, age, gender education and commuting behaviour at the postcode district level $[38,39]$. We control for income at the higher local authority district level since income data are not available for postcode districts. We also control for the average FIT rate for domestic solar PV installations, which decreased from an average rate of 42p/kWh in 2010 to slightly above 10p/kWh in 2014 . Table 1 summarises the descriptive statistics of the variables.

\begin{tabular}{|c|c|c|c|c|c|}
\hline Variables & Mean & SD & Min & Max & Source \\
\hline $\begin{array}{l}\text { Number of domestic solar PV installations per number of dwellings by postcode } \\
\text { district }\end{array}$ & 0.01 & 0.01 & 0 & 0.13 & $\mathrm{OFGEM}^{\mathrm{c}}$ \\
\hline \multicolumn{6}{|l|}{ Big Five personality traits (5-item Likert scale) } \\
\hline Conscientiousness & 3.66 & 0.14 & 2.56 & 4.56 & $\mathrm{UoC} / \mathrm{BBC}$ \\
\hline Extraversion & 3.23 & 0.15 & 1.75 & 4.25 & $\mathrm{UoC} / \mathrm{BBC}$ \\
\hline Dwelling type $\mathrm{a}^{\mathrm{a}}$ & 2.33 & 0.52 & 1.05 & 3.98 & $\mathrm{UoC} / \mathrm{BBC}$ \\
\hline Median income (GBP per week measured at the local authority district) & 499.82 & 73.34 & 365.30 & 1006.90 & ONS/NRS ${ }^{\mathrm{e}}$ \\
\hline Median age & 41.70 & 5.93 & 22 & 64 & ONS/NRS \\
\hline Gender ( $\%$ of male population) & 0.49 & 0.01 & 0.42 & 0.64 & ONS/NRS \\
\hline Education ${ }^{\mathrm{b}}$ & 3.52 & 0.47 & 2.07 & 5.56 & ONS/NRS \\
\hline
\end{tabular}

Notes: Each variable has 124,320 observations, where an observation is a postcode district month.

${ }^{a}$ Detached house/bungalow (1), semi-detached house/bungalow (2), terraced and end terraced house/bungalow (3), purpose-built block of flats/maisonettes or equivalent (4), caravan or other mobile or temporary structure (5)

${ }^{b}$ No qualification (0), Level 1 qualification (2), Level 2 qualification (3), Apprenticeship (4), Level 3 qualification (5), Level 4 qualification and above (6) 'Office of Gas and Electricity Markets

${ }^{\mathrm{d}}$ University of Cambridge/British Broadcasting Corporation

${ }^{\mathrm{c}}$ Office for National Statistics/National Records of Scotland 2011 Census data

Table 1: Summary statistics

The maps in Figure 2 and Figure 4 reveal postcode district differences in the installation rates of solar panels and the Big Five traits, and Moran's I statistics suggest that both are 
not spatially randomly distributed. The non-random patterns raise the question whether the installation rates are related to the personality trait concentrations. The next section presents the method to, firstly, test whether the spatial clustering in the installation rates of solar panels is linked to the adoption behaviour of peers and, secondly, to investigate whether the spatial concentrations of the Big Five personality traits influence these peer effects.

\section{Methodological design}

To estimate a causal influence of peer effects on people's adoption behaviour, the literature on the diffusion of technologies traditionally bases their studies on the "installed base", which is the number of agents in a social system that have already adopted a product or service $[7,18,20,41]$. The identification of peer effects by using the installed base as a predictor for current adoption behaviour requires attention regarding three main potential issues: simultaneity, homophily and correlated unobservables [6, 42].

Simultaneity can bias the estimates of peer effects if a household is influenced by adoptions of its peers, and at the same time the peers' adoption behaviour is influenced by the household. In line with previous studies, we address this issue with the fact that a decision to invest in a solar PV system does not lead to an immediate installation $[6,7]$. In the UK, the average temporal lag from the decision to adopt solar panels to completion of an installation is estimated to be three months [41]. We can therefore assume that a household's decision to adopt a solar PV system three months prior to its completion was only influenced by the installed base of its peers but not vice versa since the household did not have any experience about the installation that could be shared with others. The adoption decision is reflected three months later in the adoption rate $A R_{d, t}$, which we define as the ratio of number of solar PV installations in postcode district $d$ in month $t$ to the number of dwellings without an installation. By estimating the peer effects with the impact of the installed base from $t-3$ on the adoption rate $A R$ in $t$, we can mitigate the issue of simultaneity. 
Another bias in the peer effect estimates could be caused by the self-selection of peers (homophily), whereby people with similar attitudes and interests tend to cluster in the same spatial regions. The observed differences in the adoption rates across postcode districts may therefore reflect rather different preferences than peer effects. The bias could be further pronounced by any other correlated unobservables in a district such as local availability of solar panel contractors. We account for the possibility of homophily and correlated unobservables by (1) including control variables in our analysis (see Table 1), (2) using district fixed effects (FEs) at the postcode district level and by (3) considering time specific FEs to control for time unobservables, which can have an impact across all postcodes districts at a specific time (e.g. changes in policy programmes).

Taking the outlined model assumptions together (excluding the control variables), the adoption rate $A R_{d, t}$ can be expressed as follows:

$$
A R_{d, t}=\alpha+\beta I B_{d, t-3}+\eta_{q}+v_{t}+\varepsilon_{d, t}
$$

where $\alpha$ is the constant, $I B_{d, t-3}$ denotes the peer effects by the cumulative number of adoptions relative to the number of dwellings in $t-3$ for postcode district $d, \beta$ is the coefficient of the peer effects, $\eta_{q}$ stands for the time specific quarter $\mathrm{FEs}^{3}, v_{t}$ is a season-ofthe-year indicator (i.e. spring, summer, autumn and winter), and $\varepsilon_{d, t}$ is the error term.

In order to identify impacts of the Big Five traits on the peer effects, we use interaction terms between the aggregated postcode district means of the Big Five traits, $x_{d j}$, and the installed base $I B_{d, t-3}$, where $j=\{$ Openness to Experience, Extraversion, Conscientiousness, Agreeableness and Neuroticism\}. Together with the control variables, Equation (3) can be

\footnotetext{
${ }^{3}$ The time specific FEs are aggregated to quarter FEs in order to avoid collinearity issues with other explanatory variables that are measured on a monthly base $t$.
} 
extended to

$$
A R_{d, t}=\alpha+\beta I B_{d, t-3}+\sum_{j=1}^{5} \gamma_{j} x_{d j} I B_{d, t-3}+\sum_{k=1}^{K} \delta_{k} z_{d k} I B_{t-3}+\eta_{q}+v_{t}+\varepsilon_{d, t}
$$

where $\gamma_{j}$ denotes the coefficient for the interaction term between the peer effects and personality trait $j$ and $\delta_{k}$ is the coefficient for the interaction term between the peer effects and the $k^{\text {th }}$ control variable $z_{k}$.

The coefficients in Equations (3) and (4) are only consistently estimated under the assumption of strict exogeneity, i.e. the variance of the error term is independent of the variances of the explanatory variables. The installed base, however, is a function of past unobservables by construction whose effects are included in the error terms and therefore violate the condition of strict exogeneity. It has been shown that first-differencing accounts for this issue $[6,7,42]$, so that we can adjust Equation (3) to specify our base model as follows (Model 1):

$$
A R_{d, t}-A R_{d, t-1}=\beta\left(I B_{d, t-3}-I B_{d, t-4}\right)+\left(v_{t}-v_{t-1}\right)+\left(\varepsilon_{d, t}-\varepsilon_{d, t-1}\right),
$$

where every fourth month is dropped so that $\eta_{q}$ is cancelled out in the first-differencing process. In the same vein, taking the first difference of Equation (4) gives our Model 2:

$$
\begin{aligned}
A R_{d, t}-A R_{d, t-1} & =\beta\left(I B_{d, t-3}-I B_{d, t-4}\right)+\sum_{j=1}^{5} \gamma_{j}\left(I B_{d, t-3}-I B_{d, t-4}\right) x_{d j} \\
& +\sum_{j=k}^{K} \delta_{k}\left(I B_{d, t-3}-I B_{d, t-4}\right) z_{d k}+\left(v_{t}-v_{t-1}\right)+\left(\varepsilon_{d, t}-\varepsilon_{d, t-1}\right) .
\end{aligned}
$$

\section{Initial results}

The results of the outlined first-difference FE regressions are presented in Table 2. When excluding the Big Five traits and the control variables (Model 1), we find a statistically 


\begin{tabular}{|c|c|c|c|c|}
\hline & Model 1 & Model 2 & Model 3 & Model 4 \\
\hline \multirow[t]{2}{*}{ Installed base (IB) } & $0.0945 * * *$ & $-1.7392 *$ & -1.7858 & $-2.7104 * *$ \\
\hline & $(0.0112)$ & $(1.0355)$ & $(1.1574)$ & $(1.3739)$ \\
\hline \multirow{2}{*}{ Openness to Experience $(\mathrm{O}) \times$ IB } & & 0.0083 & $0.2067 *$ & $0.1521 * *$ \\
\hline & & $(0.0530)$ & $(0.1074)$ & $(0.0749)$ \\
\hline \multirow{2}{*}{ Conscientiousness $(\mathrm{C}) \times \mathrm{IB}$} & & 0.0849 & 0.0170 & $0.2557 * *$ \\
\hline & & $(0.0672)$ & $(0.1170)$ & $(0.1063)$ \\
\hline \multirow[t]{2}{*}{ Extraversion $(\mathrm{E}) \times \mathrm{IB}$} & & 0.0405 & 0.0602 & -0.0084 \\
\hline & & $(0.0477)$ & $(0.0792)$ & $(0.0728)$ \\
\hline \multirow{2}{*}{ Agreeableness $(\mathrm{A}) \times$ IB } & & 0.0330 & -0.0756 & 0.0270 \\
\hline & & $(0.0657)$ & $(0.1154)$ & $(0.1141)$ \\
\hline \multirow[t]{2}{*}{$\operatorname{Neuroticism}(\mathrm{N}) \times \mathrm{IB}$} & & 0.0200 & -0.0065 & -0.0388 \\
\hline & & $(0.0465)$ & $(0.0773)$ & $(0.0772)$ \\
\hline \multirow[t]{2}{*}{ Dwelling type $\times$ IB } & & $-0.0769 * *$ & $-\mathbf{0 . 0 7 5 8} * *$ & -0.0221 \\
\hline & & $(0.0391)$ & $(0.0376)$ & $(0.0448)$ \\
\hline \multirow[t]{2}{*}{ Median income $(\log ) \times$ IB } & & -0.0069 & -0.0072 & -0.0025 \\
\hline & & $(0.0106)$ & $(0.0106)$ & $(0.0091)$ \\
\hline \multirow[t]{2}{*}{ Median age $\times$ IB } & & $0.0074 * *$ & $0.0073 * *$ & $0.0113 * *$ \\
\hline & & $(0.0030)$ & $(0.0031)$ & $(0.0053)$ \\
\hline \multirow[t]{2}{*}{ Gender $\times$ IB } & & 0.3255 & 0.3218 & 0.8594 \\
\hline & & $(1.2169)$ & $(1.2363)$ & $(1.9118)$ \\
\hline \multirow[t]{2}{*}{ Education $\times$ IB } & & 0.0126 & 0.0118 & -0.0880 \\
\hline & & $(0.0304)$ & $(0.0308)$ & $(0.0637)$ \\
\hline \multirow[t]{2}{*}{ Commuting population $\times$ IB } & & $0.7287 * * *$ & $0.7031 * * *$ & 0.3671 \\
\hline & & $(0.1996)$ & $(0.2024)$ & $(0.2350)$ \\
\hline \multirow[t]{2}{*}{ Feed in Tariff $($ FIT $) \times$ IB } & & $0.0148 * * *$ & 0.0182 & $0.0329 * * *$ \\
\hline & & $(0.0006)$ & $(0.0315)$ & $(0.0012)$ \\
\hline \multirow[t]{2}{*}{$\mathrm{O} \times \mathrm{IB} \times \mathrm{FIT}$} & & & $-0.0111 * *$ & \\
\hline & & & $(0.0048)$ & \\
\hline \multirow[t]{2}{*}{$\mathrm{C} \times \mathrm{IB} \times \mathrm{FIT}$} & & & 0.0042 & \\
\hline & & & $(0.0056)$ & \\
\hline \multirow[t]{2}{*}{$\mathrm{E} \times \mathrm{IB} \times \mathrm{FIT}$} & & & -0.0011 & \\
\hline & & & $(0.0043)$ & \\
\hline \multirow[t]{2}{*}{$\mathrm{A} \times \mathrm{IB} \times \mathrm{FIT}$} & & & 0.0063 & \\
\hline & & & $(0.0060)$ & \\
\hline \multirow[t]{2}{*}{$\mathrm{N} \times \mathrm{IB} \times \mathrm{FIT}$} & & & 0.0010 & \\
\hline & & & $(0.0041)$ & \\
\hline \multirow[t]{2}{*}{$\mathrm{O} \times \mathrm{FIT}$} & & & 0.0000 & \\
\hline & & & $(0.0000)$ & \\
\hline \multirow[t]{2}{*}{$\mathrm{C} \times \mathrm{FIT}$} & & & -0.0001 & \\
\hline & & & $(0.0000)$ & \\
\hline \multirow[t]{2}{*}{$\mathrm{E} \times \mathrm{FIT}$} & & & 0.0001 & \\
\hline & & & $(0.0000)$ & \\
\hline $\mathrm{A} \times \mathrm{FIT}$ & & & 0.0000 & \\
\hline & & & $(0.0000)$ & \\
\hline $\mathrm{N} \times \mathrm{FIT}$ & & & -0.0000 & \\
\hline & & & $(0.0000)$ & \\
\hline Postcode district fixed effects & yes & yes & yes & yes \\
\hline Quarter fixed effects & yes & yes & yes & yes \\
\hline Season of year indicators & yes & yes & yes & yes \\
\hline$N$ & 69,930 & 69,930 & 69,930 & 33,670 \\
\hline$R^{2}$ & $0.02 * * *$ & $0.14 * * *$ & $0.14 * * *$ & $0.10 * * *$ \\
\hline
\end{tabular}

Notes: The dependent variable is the number of solar PV system adoptions per dwellings without a solar PV installation in a postcode district-month. The installed base is the number of installations per dwellings in a postcode district three months prior adoption. Robust standard errors clustered in postcode district are in parentheses.

$* p<0.10, * * p<0.05, * * * p<0.01$

Table 2: First-difference fixed effect model estimation of adoption rates of solar PV systems 
significant impact of the installed base (peer effects) on the adoption rate of solar PV systems. The coefficient suggests that a one percentage point increase in the installed base increases the probability of household adoption in the same postcode district three months later by 0.000945 . At the average number of 10,044 dwellings in a postcode district, 100 additional solar PV installations increase the number of adoptions three months later by $9^{4}$.

Model 2 shows the results of the regression including the interaction terms between the installed base and the Big Five traits and control variables, respectively. None of the Big Five traits shows statistically significant impact on the peer effects, so that the initial findings do not support hypothesis $1-5$.

Regarding the control variables, the negative effect of dwelling type suggests that postcode districts with more combined building units or blocks of flats exhibit weaker peer effects. The causes for this effect are likely due to the tenure and building structure. Terraced building units, for example, have multiple owners which can complicate an agreement on a solar panel installation. High buildings, such as blocks of flats, can make the installations more costly (e.g. scaffold costs). The results further suggest that postcode districts with an elder population and higher percentage of commuting individuals exhibit significantly larger peer effects. A possible explanation for the age effect is that older generations feel more obligated to conform to social norms than younger people do [43]. Travelling to work increases the chances of spotting solar panel installations which may increase the likelihood to consider such an investment for one's own home.

It is also evident that the spillovers from peers are significantly positively associated with the feed-in tariff (FIT) for solar electricity, suggesting that financial incentives facilitate behaviour to mimic the adoption decisions of neighbours. It might be that under settings of significant financial motivation, as observed for the FIT programme primarily in its initiation

\footnotetext{
${ }^{4}$ At the average number of 10,044 dwellings, a one percentage point increase in the installed base equals about 100 new installations $(0.01 * 10,044)$. This increase translates into a 0.000945 higher adoption rate, which at the average number of households without an installation of 9,957 is equivalent to 9.41 new adoptions $\left(0.000945^{*} 9,957\right)$.
} 
phase, the more subtle personality-related impacts are overwhelmed by the sheer financial incentives in the adoption decisions, possibly explaining the nonsignificant results of the personality traits.

\section{Uncovering personality trait effects behind the effects of financial subsidies}

To elaborate on whether financial incentives impede the personality trait effects, Model 3 builds on Model 2 by introducing three-way interaction terms of the peer effects, Big Five traits and FITs ${ }^{5}$. This specification is quite revealing in several ways.

First, the three-way interaction term $\mathrm{O} \times \mathrm{IB} \times$ FIT is significantly negative, suggesting that Openness to Experience does not have a unique effect on the peer effects but rather a range of effects that are contingent upon the level of the FIT. The negative sign indicates that the impact decreases with higher FITs, supporting the presumption that financial incentives mitigate the impact of personality traits.

Second, we find that postcode districts with higher levels of Openness to Experience are associated with significantly larger peer effects. The coefficient of $\mathrm{O} \times \mathrm{IB}$ indicates the impact of Openness to Experience on the peer effects if the FIT is zero, being a conditional effect. The effect of $\mathrm{O} \times \mathrm{IB}$ in Model 2 instead is unconditional (of FIT) and denotes the weighted average of the conditional marginal effects in Model 3, which depend on the distribution of the conditioning variable FIT [45]. The more observations with high FITs are present in the data, the lower is the weighted average effect because the three-way interaction term decreases the impact of Openness on the peer effects $(0.2067 \times$ IB- $0.0115 \times \mathrm{IB} \times \mathrm{FIT})$. As indicated in Model 2, the distribution of the FITs reduces the coefficient of $\mathrm{O} \times \mathrm{IB}$ to 0.0083 ,

\footnotetext{
${ }^{5}$ For further details about three-way interaction terms, see Dawson and Richter [44].
} 
resulting in an insignificant effect, thus overriding the impact of Openness to Experience on the peer effects.

Since higher FITs tend to decouple the effect of Openness to Experience on the peer effects, we expect a more distinct impact of the personality trait in the last months of the observation period, when the FITs were relatively low. Model 4 therefore restricts the observations to the period after the 01.08.2012, when the last of the most significant reductions of the FITs was implemented, lowering the average tariff for domestic solar electricity generation to almost $72 \%$ below the tariff at the inception of the FIT programme [28]. Using the same specification as in Model 2, except for the difference in the observation period, Model 4 reveals that Openness to Experience and Conscientiousness have a significantly positive impact on the peer effects.

Hence, peer effects are stronger in postcode districts with high concentrations of Openness to Experience and Conscientiousness, but only in periods of low financial incentives. These extended findings support hypothesis 2 and 5 subject to the condition of low financial subsidies, whereas hypothesis 1, 3 and 4 are not supported.

To illustrate the effects of the two personality traits, we divide the postcode districts into a group with levels below and above the mean for each trait and estimate Model 1 (see Table 3). As expected, the peer effects are stronger in postcode districts with above average levels of Openness to Experience and Conscientiousness. At the average installed base, the peer effects are translated to 2 and 6 more adoptions for every 100 installations in the high-Openness and -Conscientiousness group, respectively, compared to the groups with below-average levels of these two personality traits ${ }^{6}$.

\footnotetext{
${ }^{6}$ The derivation of the additional adoptions is illustrated with the example of Openness to Experience $(\mathrm{O})$ : $\beta_{\text {High O }}-\beta_{\text {Low O }}=\Delta_{O}=0.018$

$\frac{\text { Adoptions }}{1 \text { installation }}=\frac{0.01 \times \Delta_{O} \times \text { Average \# of dwellings in postcode district without solar panel adoption }}{1 \mathrm{pp} \mathrm{increase} \mathrm{in} \mathrm{average} \mathrm{installed} \mathrm{base}}=\frac{0.01 \times 0.018 \times 9,957}{100.44}=0.02$
} 


\begin{tabular}{lllll}
\hline & Low O & High O & Low C & High C \\
\hline Installed base (IB) & $0.0847 * * *$ & $0.1031^{* * *}$ & $0.0600^{* * *}$ & $0.1214^{* * *}$ \\
& $(0.0123)$ & $(0.0177)$ & $(0.0180)$ & $(0.0124)$ \\
Postcode district fixed effects & yes & yes & yes & yes \\
Quarter fixed effects & yes & yes & yes & yes \\
Season of year indicators & yes & yes & yes & yes \\
$N$ & 39,798 & 30,132 & 34,317 & 35,613 \\
$R^{2}$ & $0.02^{* * *}$ & $0.02^{* * *}$ & $0.01^{* * *}$ & $0.03 * * *$ \\
\hline
\end{tabular}

Notes: The dependent variable is the number of solar PV system adoptions per dwellings without a solar PV installation in a postcode district-month. The installed base is the number of installations per dwellings in a postcode district three months prior adoption. Robust standard errors clustered in postcode district are in parentheses.

$* p<0.10, * * p<0.05, * * * p<0.01$

Table 3: Peer effects for high and low levels of Openness to Experience $(\mathrm{O})$ and Conscientiousness (C) in Model 1

\section{Discussion}

Prior studies have noted the importance of personality traits driving energy saving behaviour under peer pressure $[16,17]$. To the best of our knowledge, this is the first study that elaborates on the link between personality and peer effects for high-cost renewable energy systems.

Maps of the Big Five personality traits show significant personality clustering across postcode districts in the UK (see Figure 4). Literature on geographical psychology suggests several mechanisms for the spatial distribution of the personality traits. Research on selective migration indicates that people tend to move to places that satisfy and reinforce their psychological needs. High-Openness and extraverted individuals are found to move from their home states to a different state, whereas agreeable individuals rather stay in their hometowns $[46,47]$. Social influence proposes that the behaviour of people within the local environment may shape one own's attitudes and actions $[36,48]$. For example, places with a high proportion of anxious people/Neuroticism may increase the level of negative affect of other people 
[37]. Geographical concentrations of personality traits may be also explained by ecological influence. Several studies show that the natural and built environment, such as climate, ethnic diversity and green spaces can affect individual's psychological processes. Living close to green spaces in an urban environment, for instance, is found to reduce mental distress and increase well-being [49]. Another example is the observation that regions with high levels of infectious diseases in the past report lower levels of Openness and Extraversion-traits that possibly reduce the risk of disease transmission through cautious behaviour (e.g. fewer social interactions) [50].

It was hypothesised that the spatial concentrations of the Big Five personality traits influence households' adoption of solar panels under peer pressure. Overall, the results suggest that peer effects are stronger in postcode districts with high concentrations of Openness to Experience and Conscientiousness. The finding for Openness to Experience supports the outlined hypothesis that increased interpersonal communication and interconnectedness in social networks of high-Openness individuals facilitate exchange of information, so that they are more likely to be influenced by their neighbours' installation decisions. Openness also represents creativity, curiosity and intellect [27], which may rather trigger interest in considering a solar panel installation if spotted on neighbours' roof. The result is consistent with the study of Shen et al. [16] who found that high-Openness individuals are more influenced by the their neighbours' energy saving behaviour. Stronger peer effects in high-Conscientiousness districts may be explained by conscientious individuals' strive for responsibility to carry out their duties and following norms that are considered right $[24,25]$. Also, such individuals might be more aware of their surroundings, meaning that they rather recognise new solar panel installations in their neighbourhood.

It is further observed that the impact of Openness to Experience on the peer effects increases with decreasing financial incentives for solar panels, and the impact for Conscientiousness is only evident towards the end of the observation period, when the incentives 
were significantly reduced. This suggests that financial motivators tend to override more subtle personality trait influences, which are possibly manifested only in marginal investment decisions. The result falls in line with findings of previous studies showing that if a behaviour is spurred by social norms (e.g. ethics, moral), the inclusion of financial incentives can undermine these normative considerations and discourage pro-environmental behaviour $[13,51]$

Several limitations of this study need to be acknowledged. The social systems are defined by postcode districts within which the peer effects are assumed to spread, but spillovers from peers may well emerge across the district boundaries. Another limitation is that the personality sample is self-selected and, therefore, may not be completely representative of the population. Finally, the causal processes for the impact of personality on the peer effects are not explicitly measured (e.g. communication behaviour, awareness). The observed personality effects, therefore, cannot be assigned to a specific causal mechanism. The effect of Openness to Experience, for instance, can be attributed to increased communication behaviour or higher willingness to scrutinise a solar PV investment.

\section{Conclusions and policy implications}

This study set out to examine the influence of personality traits on peer effects for domestic solar PV systems. We find that spatial clustering of Openness to Experience and Conscientiousness have significant impact on how strongly additional solar PV installations in a postcode district affect succeeding adoption rates. We find evidence that for one additional solar PV installation, the probability of an adoption in postcode districts with above-average levels of Openness to Experience increases on average by 2 percentage points more compared to districts with below-average levels of Openness to Experience, while the probability of an adoption in postcode districts with above-average levels of Conscientiousness increases by 6 percentage points more. The findings suggest that the impact of the personality traits on 
the peer effects only unfold under marginal investment conditions. When strong financial incentives are offered, the decision to emulate one's peers and install a solar PV system appears to depend solely on the financial benefits and differences in personality traits lose significance.

The results of this study can provide guidance for policy makers and vendors promoting solar PV systems and other green technologies. First, programmes that campaign green technologies with social interactions such as community-based information sessions should be predominantly organised in social systems with a high degree of interpersonal communication, in which the information about the technology spreads faster. Our study suggests that areas with high concentrations of Openness to Experience should be favoured in this regard. Second, advertisements of green technology products directly at the site of installations might be more effective in combination with peer effects. Advertisements for solar panels, for example, could yield more attraction if placed directly at their installation sites. Our findings indicate that such measures should be concentrated in areas with high aggregate-levels of Conscientiousness, where households might feel more obligated to follow norms and are possibly more aware about the installations and advertisements in their neighbourhood. Third, from the business point of view, levering informational measures through peer effects by targeting districts with specific personality trait concentrations might be successful for introducing a novel green technology even when no financial incentives are granted (e.g. promotional discounts, governmental subsidies). Combining financial with informational measures might be less effective because financial incentives tend to decouple the amplifying effects of personality from the peer effects. Under settings in which behaviour is motivated by social norms, financial subsidies may even disincentivise pro-environmental decisions [13].

In sum, this study contributes to the literature on peer effects by providing first empirical evidence that social spillovers in the context of green technology investments depend on 
geographical concentrations of personality traits. The findings demonstrate that the importance of personality for peer effects is subject to financial incentives offered for such investments. Future research might use experimental individual-level data to disentangle the causal mechanisms for the personality impacts on the peer effects (e.g. explicitly measure communication behaviour of Openness to Experience individuals), and elaborate on the threshold beyond which financial motivators tend to marginalise personality effects. 


\section{Acknowledgments}

Ante Busic-Sontic acknowledges the financial support of the Department of Land Economy, Cambridge and Franz Fuerst the continuous and generous support of the Cambridge University Land Society in enabling his research activities. 


\section{References}

[1] R. B. Cialdini, M. R. Trost, Social influence: Social norms, conformity and compliance, in: D. T. Gilbert, S. T. Fiske, G. Lindzey (Eds.), The handbook of social psychology, Vols. 1-2, McGraw-Hill, New York, US, 4th edn., ISBN 0-19-521376-9, 1998, pp. $151-192$.

[2] E. M. Rogers, Diffusion of Innovations, Simon and Schuster, 5th edn., 2003.

[3] G. Di Palma, H. McClosky, Personality and Conformity: The Learning of Political Attitudes, The American Political Science Review, 64 (1970), pp. 1054-1073.

[4] EU, Directive 2009/28/EC of the European Parliament and of the Council of 23 April 2009 on the promotion of the use of energy from renewable sources and amending and subsequently repealing Directives 2001/77/EC and 2003/30/EC, Official Journal of the European Union, L 140/16 (2009), pp. 16-62.

[5] DECC, Review of the Feed-in Tariffs Scheme, Department of Energy and Climate Change, 2015.

[6] B. Bollinger, K. Gillingham, Peer Effects in the Diffusion of Solar Photovoltaic Panels, Marketing Science, 31 (2012), pp. 900-912.

[7] M. Graziano, K. Gillingham, Spatial patterns of solar photovoltaic system adoption: The influence of neighbors and the built environment, Journal of Economic Geography, 15 (2015), pp. 815-839. 
[8] F. Fornara, P. Pattitoni, M. Mura, E. Strazzera, Predicting intention to improve household energy efficiency: The role of value-belief-norm theory, normative and informational influence, and specific attitude, Journal of Environmental Psychology, 45 (2016), pp. $1-10$.

[9] J. M. Nolan, P. W. Schultz, R. B. Cialdini, N. J. Goldstein, V. Griskevicius, Normative Social Influence is Underdetected, Personality and Social Psychology Bulletin, 34 (2008), pp. 913-923.

[10] H. Allcott, S. Mullainathan, Behavior and Energy Policy, Science, 327 (2010), pp. 1204-1205.

[11] P. J. Ferraro, J. J. Miranda, M. K. Price, The Persistence of Treatment Effects with Norm-Based Policy Instruments: Evidence from a Randomized Environmental Policy Experiment, American Economic Review, 101 (2011), pp. 318-22.

[12] N. J. Goldstein, R. B. Cialdini, V. Griskevicius, A room with a viewpoint: Using social norms to motivate environmental conservation in hotels, Journal of Consumer Research, 35 (2008), pp. 472-482.

[13] J. W. Bolderdijk, L. Steg, Promoting sustainable consumption: the risks of using financial incentives, in: L. A. Reisch, J. Thogersen (Eds.), Handbook of Research on Sustainable Consumption, Edward Elgar Publishing, 2015, pp. 328-342.

[14] H. Allcott, Social norms and energy conservation, Journal of Public Economics, 95 (2011), pp. 1082-1095.

[15] C. Fischer, Feedback on household electricity consumption: a tool for saving energy?, Energy Efficiency, 1 (2008), pp. 79-104.

[16] M. Shen, Q. Cui, L. Fu, Personality traits and energy conservation, Energy Policy, 85 (2015), pp. 322-334. 
[17] S. Khashe, A. Heydarian, B. Becerik-Gerber, W. Wood, Exploring the effectiveness of social messages on promoting energy conservation behavior in buildings, Building and Environment, 102 (2016), pp. 83-94.

[18] F. M. Bass, A New Product Growth for Model Consumer Durables, Management Science, 15 (1969), pp. 215-227.

[19] H. Xiong, D. Payne, S. Kinsella, Peer effects in the diffusion of innovations: Theory and simulation, Journal of Behavioral and Experimental Economics, 63 (2016), pp. $1-13$.

[20] V. Mahajan, E. Muller, F. M. Bass, New Product Diffusion Models in Marketing: A Review and Directions for Research, Journal of Marketing, 54 (1990), pp. 1-26.

[21] R. Peres, E. Muller, V. Mahajan, Innovation diffusion and new product growth models: A critical review and research directions, International Journal of Research in Marketing, 27 (2010), pp. 91-106.

[22] C. Van den Bulte, S. Stremersch, Social Contagion and Income Heterogeneity in New Product Diffusion: A Meta-Analytic Test, Marketing Science, 23 (2004), pp. 530-544.

[23] L. R. Goldberg, The development of markers for the Big-Five factor structure, Psychological Assessment, 4 (1992), pp. 26-42.

[24] R. R. McCrae, P. T. Costa, Personality in Adulthood: A Five-factor Theory Perspective, Guilford Press, ISBN 978-1-57230-827-5, 2003.

[25] P. T. Costa, R. R. MacCrae, Revised NEO Personality Inventory (NEO PI-R) and NEO Five-Factor Inventory (NEO FFI): Professional manual, Psychological Assessment Resources, 1992. 
[26] R. R. McCrae, P. T. Costa Jr, A Five-Factor Theory of Personality, in: L. A. Pervin, O. P. John (Eds.), Handbook of Personality: Theory and Research, Guilford Press, New York, 2nd edn., 1999, pp. 139-153.

[27] O. P. John, S. Srivastava, The Big Five trait taxonomy: History, measurement, and theoretical perspectives, in: Handbook of personality: Theory and research, vol. 2, Guilford Press, New York, 1999, pp. 102-138.

[28] OFGEM, Feed-in Tariff: Guidance for Renewable Installations (Version 10.2), Office of Gas and Electricity Markets, 2016, $\quad$ https://www.ofgem.gov.uk/system/files/docs/2016/06/feedin_tariff_guidance_for_renewable_installations_v10.2.pdf (Assessed on 13 December, 2016).

[29] University of Cambridge (Department of Psychology) and British Broadcasting Corporation, BBC Big Personality Test, 2009-2011: Dataset for Mapping Personality across Great Britain, UK Data Service, 2015, http://doi.org/10.5255/UKDA-SN-7656-1 (Assessed on 24 June, 2017).

[30] A. Busic-Sontic, N. V. Czap, F. Fuerst, The role of personality traits in green decisionmaking, Journal of Economic Psychology, 62 (2017), pp. 313-328.

[31] D. A. Cobb-Clark, S. Schurer, The stability of big-five personality traits, Economics Letters, 115 (2012), pp. 11-15.

[32] S. Brown, K. Taylor, Household finances and the "Big Five" personality traits, Journal of Economic Psychology, 45 (2014), pp. 197-212.

[33] G. Matthews, I. J. Deary, M. C. Whiteman, Personality Traits, Cambridge University Press, 3rd edn., ISBN 978-0-521-71622-2, 2009. 
[34] R. Riccelli, N. Toschi, S. Nigro, A. Terracciano, L. Passamonti, Surface-based morphometry reveals the neuroanatomical basis of the five-factor model of personality, Social Cognitive and Affective Neuroscience, 12 (2017), pp. 671-684.

[35] M.-T. Lo, D. A. Hinds, J. Y. Tung, C. Franz, C.-C. Fan, Y. Wang, O. B. Smeland, A. Schork, D. Holland, K. Kauppi, N. Sanyal, V. Escott-Price, D. J. Smith, M. O’Donovan, H. Stefansson, G. Bjornsdottir, T. E. Thorgeirsson, K. Stefansson, L. K. McEvoy, A. M. Dale, O. A. Andreassen, C.-H. Chen, Genome-wide analyses for personality traits identify six genomic loci and show correlations with psychiatric disorders, Nature Genetics, 49 (2017), pp. 152-156.

[36] R. M. Bond, C. J. Fariss, J. J. Jones, A. D. I. Kramer, C. Marlow, J. E. Settle, J. H. Fowler, A 61-million-person experiment in social influence and political mobilization, Nature, 489 (2012), pp. 295-298.

[37] P. J. Rentfrow, M. Jokela, M. E. Lamb, Regional Personality Differences in Great Britain, PLoS ONE, 10 (2015), p. e0122245.

[38] ONS, 2011 Census data, Office for National Statistics, 2017, https://www.nomisweb.co.uk (Assessed on 26 June, 2017).

[39] NRS, 2011 Census data, National Records of Scotland, 2017, http://www.scotlandscensus.gov.uk (Assessed on 27 June, 2017).

[40] P. A. P. Moran, Notes on Continuous Stochastic Phenomena, Biometrika, 37 (1950), pp. $17-23$.

[41] L. L. Richter, Social Effects in the Diffusion of solar Photovoltaic Technology in the UK, Energy Policy Research Group Cambridge, 2014.

[42] S. Narayanan, H. S. Nair, Estimating Causal Installed-Base Effects: A Bias-Correction Approach, Journal of Marketing Research, 50 (2013), pp. 70-94. 
[43] A. Goerres, Why are Older People More Likely to Vote? The Impact of Ageing on Electoral Turnout in Europe, The British Journal of Politics \& International Relations, 9 (2007), pp. 90-121.

[44] J. Dawson, A. W. Richter, A Significance Test of Slope Differences for Three-way Interactions in Moderated Multiple Regression Analysis, Aston Business School, ISBN 978-1-85449-594-5, 2004.

[45] T. Brambor, W. R. Clark, M. Golder, Understanding Interaction Models: Improving Empirical Analyses, Political Analysis, 14 (2006), pp. 63-82.

[46] M. Jokela, Personality predicts migration within and between U.S. states, Journal of Research in Personality, 43 (2009), pp. 79-83.

[47] P. J. Rentfrow, M. Jokela, Geographical Psychology, Current Directions in Psychological Science, 25 (2016), pp. 393-398.

[48] G. Hofstede, R. R. McCrae, Personality and culture revisited: Linking traits and dimensions of culture, Cross-cultural research, 38 (2004), pp. 52-88.

[49] M. P. White, I. Alcock, B. W. Wheeler, M. H. Depledge, Would You Be Happier Living in a Greener Urban Area? A Fixed-Effects Analysis of Panel Data, Psychological Science, 24 (2013), pp. 920-928.

[50] M. Schaller, D. R. Murray, Pathogens, personality, and culture: disease prevalence predicts worldwide variability in sociosexuality, extraversion, and openness to experience, Journal of Personality and Social Psychology, 95 (2008), pp. 212-221.

[51] M. J. J. Handgraaf, M. A. Van Lidth de Jeude, K. C. Appelt, Public praise vs. private pay: Effects of rewards on energy conservation in the workplace, Ecological Economics, 86 (2013), pp. 86-92. 